LEBEN, EINE LNERHÖRTE BEGEBENHEIT 


\title{
FRANCO PRATTICO
}

\section{Leben, \\ eine unerhörte Begebenheit}

\section{VOM CHAOS ZUM BEWUSSTSEIN}

Aus dem Italienischen von Ulrich Prill

\author{
J.B. METZLERSCHE \\ VERLAGSBUCHHANDLUNG \\ STUTTGART
}




\section{CIP-Titelaufnahme der Deutschen Bibliothek}

\section{Prattico, Franco:}

Leben, eine unerhörte Begebenheit : vom Chaos zum

BewuBtsein / Franco Prattico. Aus dem Ital. von Ulrich Prill.

- Stuttgart : Metzler, 1991

ISBN 978-3-476-00735-3

ISBN 978-3-476-00735-3

ISBN 978-3-476-03340-6 (eBook)

DOI 10.1007/978-3-476-03340-6

Dieses Werk einschließlich aller seiner Teile ist urheberrechtlich geschützt. Jede Verwertung außerhalb der engen Grenzen des Urheberrechtsgesetzes ist ohne Zustimmung des Verlages unzulässig und strafbar. Das gilt insbesondere für Vervielfältigungen, Übersetzungen, Mikroverfilmungen und die Einspeicherung und Verarbeitung in elektronischen Systemen.

(C) 1991 Springer-Verlag GmbH Deutschland Ursprünglich erschienen bei J. B. Metzlersche Verlagsbuchhandlung und Carl Ernst Poeschel Verlag GmbH in Stuttgart 1991 


\title{
I N H A L T
}

\author{
Einleitung
}

Seite 7

Vom Nichts zum Ganzen

Seite 11

Der kosmische Same 11

Die zerbrochene Symmetrie 14

Das Geheimnis der Materie 16

Statisch oder dynamisch? 19

Das Universum nimmt Gestalt an

Seite 24

Die Galaxienfabrik 24

"Löcher« im Urknall 27

Quantenkosmologie

Seite 32

Das Universum, eine »Gratisleistung « 32

Im Reich der Virtualität 36

Unendlich viele mögliche Welten 39

Das anthropische Prinzip 42

Der Stoff, aus dem das Universum ist

Seite 46

Das Wasserstoffatom 46

An den Quellen der Materie 50

Wolkengeboren 54

Das Leben, eine unerhörte Begebenheit

Seite 57

Vom Anorganischen zum Lebendigen 57

Ein maßgeschneiderter Planet 62 
So viele Theorien...65

... über einen Ursprung 70

Ein Planet wird erobert

Seite 74

Das " unsterbliche Tier « 74

Metaphysik der "notwendigen Evolution « 77

Eine List des Gens 83

Der Kosmos modelliert das Leben

Seite 86

Katastrophe in der Kreidezeit 86

Todeszyklen 91

Der unaufhaltsame Aufstieg der Säugetiere 94

Die Geburt des Menschen

Seite 98

Kampf der Schwerkraft 98

Driftende Kontinente 101

Der Zauberschlüssel Sprache 106

Noch ein "Geschenk « des Zufalls 110

Die Materie denkt sich selbst

Seite 114

Das Neuron, eine intelligente Einheit 114

Die Beziehung Geist - Gehirn 120

Anmerkungen

Seite 132 